Background and aims If infants fail to initiate spontaneous breathing after birth, international guidelines recommend positive pressure ventilation (PPV). However, mask PPV remains challenging with leakage occurring commonly. Despite a variety of available facemasks, none has been systemically studied in newborn infants. We aimed to determine if using a Fisher and Paykel (FP) round facemask would reduce mask leak compared to using a Laerdal round facemask during mask PPV in preterm infants.

Methods From April to September 2013, at the Royal Alexandra Hospital, newborn infants.

Results Fifty-eight preterm infants ( $\mathrm{n}=29$ in each group) were enrolled; mean \pm SD gestation $28 \pm 3$ weeks; birth weight 1210 $\pm 448 \mathrm{~g}, 30(52 \%)$ male, 39(67\%) born by caesarean section. Apgar scores at 1 and 5 min were $5 \pm 3$ and $7 \pm 2$, respectively. Infants randomised to the FP facemask and Laerdal facemask had similar mask leak ( $37 \pm 17 \%$ vs. $33 \pm 12 \%$, respectively, p $=0.30)$ and tidal volume $(7.3 \pm 3.0 \mathrm{~mL} / \mathrm{kg}$ vs. $6.9 \pm 2.7 \mathrm{~mL} /$ $\mathrm{kg}, \mathrm{p}=0.73$ ) during PPV. There were no significant differences in ventilation rate, inflation time or airway pressures between groups.

Conclusions The use of either facemask during PPV in the delivery room yields similar mask leak.

\section{0-069a VIDEOLARYNGOSCOPY AS AN INTUBATION TRAINING TOOL FOR NEONATAL TRAINEES - A RANDOMISED CONTROLLED TRIAL}

J O'Shea, M Thio, COF Kamlin, L McGrory, J Jubal, C Roberts, C Kuschel, PG Davis. Department of Newborn Research, Royal Women's Hospital, Melbourne, Australia

\subsection{6/archdischild-2014-307384.138}

Background and aims Endotracheal intubation is a mandatory skill for neonatal trainees. However, inexperienced trainees have success rates $<50 \%$. We compared intubations supervised by an instructor watching a videolaryngoscope screen with the traditional method where the instructor does not have this view.

Methods RCT (ANZCTR\# 12613000159752) at The Royal Women's Hospital, Melbourne. Eligible intubations were those performed orally, in infants without facial or airway anomalies, in the delivery room or in NICU, by trainees with $<6$ months experience. Intubations were randomised to videolaryngoscope screen visible to the instructor (intervention) or covered (control). Primary outcome was first attempt intubation success rate confirmed by colorimetric detection of expired $\mathrm{CO}_{2}$. A sample size of 206 provided $80 \%$ power to detect a $20 \%$ difference in success rates $(50 \%$ vs. $70 \%)$.

\begin{tabular}{|c|c|c|c|}
\hline & Control $(n=102)$ & Intervention $(n=104)$ & $\mathbf{P}$ \\
\hline Corrected gestation $(w)^{*}$ & $29(27-32)$ & $29(27-32)$ & 0.82 \\
\hline Weight $(g)^{*}$ & $1125(816-1569)$ & 1172.5 (819-1884) & 0.35 \\
\hline Success rate $-\mathrm{n}(\%)$ & $42 / 102(41.2 \%)$ & $69 / 104(66.3 \%)$ & $<0.001$ \\
\hline \multicolumn{4}{|l|}{ Success rate with } \\
\hline premedication - n (\%) & $35 / 79(44.3 \%)$ & $56 / 78(71.8 \%)$ & $<0.001$ \\
\hline \multicolumn{4}{|l|}{ Success rate without } \\
\hline premedication - n (\%) & $7 / 23(30.4 \%)$ & $13 / 26(50 \%)$ & 0.164 \\
\hline Lowest $\mathrm{SpO}_{2}(\%)^{*}$ & $69(46-82)$ & $70(47.5-83)$ & 0.88 \\
\hline Lowest heart rate $(\mathrm{bpm})^{*}$ & $151(139-162)$ & $150(134.5-163.5)$ & 0.99 \\
\hline Duration of attempt $(s)^{*}$ & $53(41-70)$ & $51(39-63)$ & 0.15 \\
\hline
\end{tabular}

Results

Conclusions Intubation success rates of inexperienced doctors were significantly improved, OR 2.81 (95\% CI 1.54-5.17), when the instructor was able to share their view on a videolaryngoscope screen.

\section{Nephrology I}

\section{0-070 HAEMODYNAMIC IMPACT OF THE CONNECTION OF CONTINUOUS RENAL REPLACEMENT THERAPY IN CRITICALLY ILL CHILDREN}

B Toledo, MJ Santiago, SN Fernández, M García, AC Sánchez, J Del Castillo, J López-Herce. PICU, Hospital General Universitario Gregorio Marañón, Madrid, Spain

\subsection{6/archdischild-2014-307384.139}

Background Continuous Renal Replacement Therapies (CRRT) are the treatment of choice for critically ill children with Acute Renal Injury. Hypotension after starting CRRT is frequent but there are no studies that have analysed their incidence and importance.

Patients and methods A prospective, observational study was performed including critically ill children treated with CRRT between October 2009 and December 2013. Hemodynamic data and connection characteristics were collected before, during and $60 \mathrm{~min}$ after CRRT circuit connection. Hypotension with the connection was defined as a decrease in mean arterial pressure $>20 \%$ from baseline and/or intravenous fluid expansion and/or if increase in vasopressors was required.

Results 161 connections in 36 children (median age 18.8 months) were analysed. 28 patients $(77.8 \%)$ were in the postoperative period of cardiac surgery, $94 \%$ on mechanical ventilation and $86.1 \%$ with vasopressors. The circuit prime was discarded in $8.7 \%$ of connections, the heparinised prime was infused in $18 \%$ and the circuit was previously primed witha colloid (albumin in $77.5 \%$ ) or crystalloid without heparine in $73.3 \%$. Hypotension occurred in $49.7 \%$ of connections with a median of 5 min after the beginning. In $38.5 \%$ of the connections fluid expansion was required and in $12.4 \%$ vasopressors were increased. There was no hypotension relation to age or weight. Previous priming of the circuit reduced the frequency of hypotension to $44.6 \%$ vs. $71.4 \%$ ( $p=0.004)$.

Conclusions Hypotension after CRRT connection is very frequent in critically ill children. Priming the circuit improves hemodynamic tolerance of the connection.

\section{0-071 SALT-SPARING DIURETIC ACTION OF A UREA ANALOGUE INHIBITOR OF UREA TRANSPORTERS UT-A AND UT-B IN RATS}

${ }^{1} \mathrm{O}$ Cil, ${ }^{2} \mathrm{C}$ Esteva-Font, ${ }^{3} \mathrm{ST}$ Tas, ${ }^{2} \mathrm{~S}$ Lee, ${ }^{3} \mathrm{M}$ Ertunc, ${ }^{2} \mathrm{AS}$ Verkman. ${ }^{1}$ Depatment of Pediatrics, Hacettepe University, Faculty of Medicine, Ankara, Turkey; ${ }^{2}$ Departments of Medicine and Physiology, University of California San Francisco, San Francisco, USA; ${ }^{3}$ Depatment of Pharmacology, Hacettepe University, Faculty of Medicine, Ankara, Turkey

\subsection{6/archdischild-2014-307384.140}

Background and aims Urea is end metabolite of protein metabolism and is crucial for generation of hypertonic renal medulla. Urea transport to medullary interstitium is facilitated by urea transporters (UT-A and UT-B). UT inhibitors have potential use as a novel class of salt-sparing diuretics.

Methods UT inhibitor effect of urea analogue dimethylthiourea (DMTU) was investigated and characterised in cell-based assays. 
Kidney function tests were investigated in both 1-day and 7-days DMTU-treated (500 mg/kg ip initially, then $125 \mathrm{mg} / \mathrm{kg}$ ip every $12 \mathrm{~h}$ ) rats. The effect of DMTU on maximum urine concentrating function was investigated in low (6\%) and normal (20\%) protein-fed rats.

Results DMTU non-competitively inhibited UT-A and UT-B with $\mathrm{IC}_{50}$ of $\sim 3 \mathrm{mM}$. Following $500 \mathrm{mg} / \mathrm{kg}$ ip injection, plasma DMTU concentration was initially $10 \mathrm{mM}$ (plasma elimination $\mathrm{t}_{1 / 2} \sim 10 \mathrm{~h}$ ) and urine DMTU concentration was $>20 \mathrm{mM}$ for $12 \mathrm{~h}$. DMTUtreated rats showed reversible, sustained reduction in urine osmolality $(>60 \%)$ and 3 -fold increased daily urine output. DMTU increased renal electrolyte-free water excretion without altering solute excretion. DMTU impaired maximum urinary concentrating function only in normal protein-fed rats. Methylurea, a non-UT inhibitor urea analogue, had no effect on either urine volume or osmolality. DMTU-treated rats had greater diuresis and much reduced urinary salt loss compared to that of furosemide-treated rats.

Conclusions These results establish a rat model of sustained UT inhibition and demonstrate remarkable diuretic efficacy of UT inhibition. Prominent effect of UT inhibitors on net renal water excretion implies a novel therapeutic strategy for treatment of oedema in hypervolemic diseases.

\section{Neuromuscular Disorders}

\section{0-072 INCREASED INTRACRANIAL PRESSURE IN CHILDREN WITH ACUTE DISSEMINATED ENCEPHALOMYELITIS}

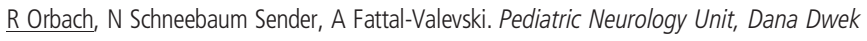
Children's Hospital Tel-Aviv Sourasky Medical Center, Tel Aviv, Israel

\subsection{6/archdischild-2014-307384.141}

Introduction Lumbar puncture (LP) is routinely performed as part of the workup evaluation of suspected acute disseminated encephalomyelitis (ADEM). Mild pleocytosis and/or increased CSF protein concentration are common findings in ADEM. However, the CSF opening pressure, reflecting the intracranial pressure (ICP), has not been acknowledged to date in the literature.

Methods Chart reviews of paediatric patients hospitalised in the Tel-Aviv Sourasky medical centre, between 2005-2013, that were diagnosed with ADEM, were identified retrospectively.

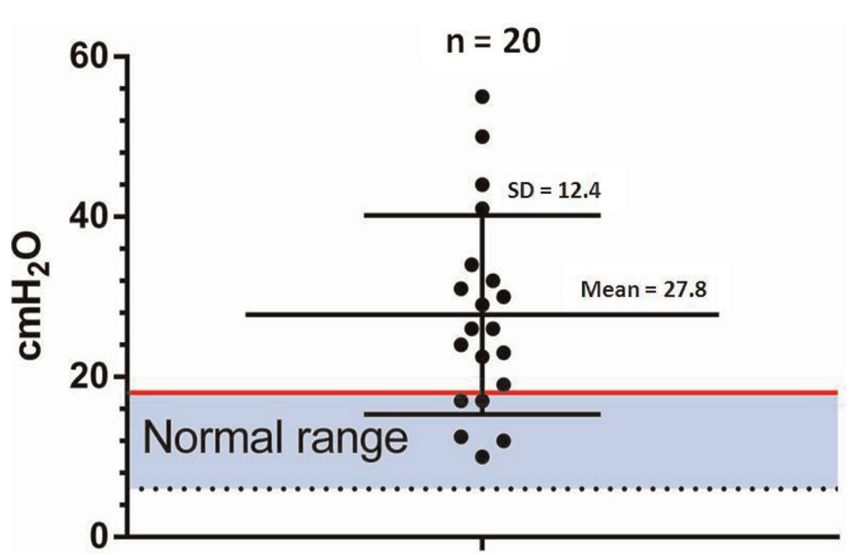

Abstract 0-072 Figure 1 CSF opening pressure of 20 patients with ADEM. Each dot represents a patient, the blue zone indicates the normal limits of CSF opening pressure, the upper normal limit of $18 \mathrm{cmH} 20$ marked as a red line. The scatter plot shows that most patients had elevated opening pressures with 4 patients having values beyond $40 \mathrm{cmH} 20$.
Results Among 35 children diagnosed with ADEM, 20 who had documented CSF opening pressure comprised the study group. The mean age was $5.3 \pm 4.1$ years, ten males (50\%); Mean CSF opening pressure was $27.8 \pm 12.4 \mathrm{cmH}_{2} \mathrm{O}$, range 10-55 $\mathrm{cmH}_{2} \mathrm{O}$. Considering the upper normal limit of CSF opening pressure in this age group $\left(18 \mathrm{cmH}_{2} \mathrm{O}\right), 15 / 20$ (75\%) patients had elevated pressure and one sample t-test comparison showed significant elevated CSF opening pressure among patients with ADEM $\left(\mathrm{p}_{\mathrm{v}}=0.0023,95 \%\right.$ CI 3.9-15.6). Minimal pleocytosis was present in seven samples $\left(\right.$ median $=2$ cells $/ \mathrm{mm}^{2}$ ). Eighteen out of twenty (90\%) patients had clinical complaints/signs that can be explained by increased ICP (drowsiness/encephalopathy $\mathrm{n}$ $=18$, vomiting $\mathrm{n}=8$, headache $\mathrm{n}=8$ ).

Discussion This study highlights that increased ICP is a prominent patho-physiologic change occurring in the CNS of ADEM patients. In our cohort, this was the most common CSF abnormal finding, independent of pleocytosis level. This observation is in line with the common non-focal neurological symptoms and signs and the beneficial effect of steroid treatment in ADEM. Furthermore, it suggests a potential efficacy of other reducing ICP treatments in ADEM.

\section{0-073 TOTAL AND REGIONAL CORPUS CALLOSUM VOLUMES ARE RELATED TO INTELLIGENCE AND MOTOR FUNCTION IN DYSKINETIC CEREBRAL PALSY}

1) Ballester-Plané, ${ }^{1} \mathrm{O}$ Laporta-Hoyos, ${ }^{2} \mathrm{~A}$ Macaya, ${ }^{3} \mathrm{P}$ Póo, ${ }^{4} \mathrm{M}$ Meléndez, ${ }^{5} \mathrm{E}$ Vázquez, ${ }^{5}$ Delgado, ${ }^{1} \mathrm{~A}$ Narberhaus, ${ }^{4} \mathrm{~T}$ Castelló, ${ }^{3} \mathrm{ME}$ Russi, ${ }^{6} \mathrm{~V}$ Tenorio, ${ }^{7} \mathrm{~L}$ Zubiaurre-Elorza, ${ }^{8} \mathrm{C}$ Torroja-Nualart, ${ }^{1} \mathrm{D}$ Segarra, ${ }^{1} \mathrm{R}$ Pueyo. ${ }^{1}$ Psychiatry and Clinical Psychobiology, University of Barcelona, Barcelona, Spain; ${ }^{2}$ Paediatric Neurology, Hospital Vall d'Hebron, Barcelona, Spain; ${ }^{3}$ Neurology, Hospital Sant Joan de Déu, Barcelona, Spain; ${ }^{4}$ Physical Medicine and Rehabilitation, Hospital Vall d'Hebron, Barcelona, Spain; ${ }^{5}$ Radiology, Hospital Vall $d^{\prime}$ Hebron, Barcelona, Spain; ${ }^{6}$ Institute Clinic of Gynecology Obstetrics and Neonatology, Hospital Clínic de Barcelona, Barcelona, Spain; ${ }^{7}$ The Brain and Mind Institute, Western University, Ontario, Canada; ${ }^{8}$ Methodology and Behavioral Sciences, University of Barcelona, Barcelona, Spain

\subsection{6/archdischild-2014-307384.142}

Background The relationship between corpus callosum (CC) morphology and mainly motor outcomes has been studied in spastic cerebral palsy (CP) but not yet in dyskinetic CP, which

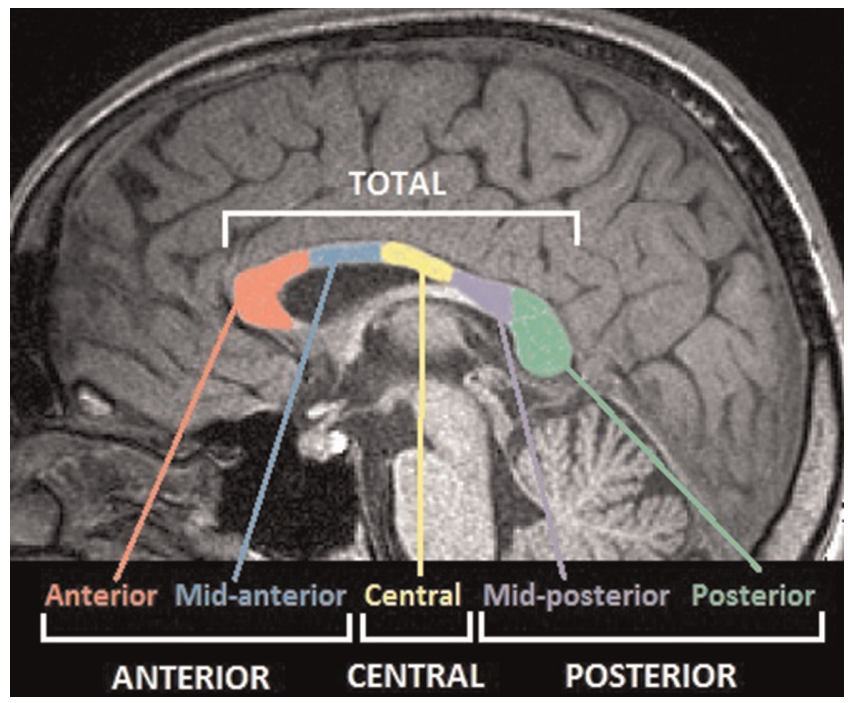

Abstract 0-073 Figure 1 CC subdivisions generated by Freesurfer (in colour) 